Herz 2023 $\cdot 48: 55-63$

https://doi.org/10.1007/s00059-021-05091-6

Received: 1 October 2021

Revised: 9 November 2021

Accepted: 16 November 2021

Published online: 10 January 2022

(c) The Author(s) 2022

\section{Sparse 3D contrast-enhanced whole-heart imaging for coronary artery evaluation}

\author{
Uzair Ansari ${ }^{1,2,3}$ (D) Sonja Janssen ${ }^{4} \cdot$ Stefan Baumann ${ }^{1,2,3} \cdot$ Martin Borggrefe $^{1,2,3} \cdot$ \\ Stephan Waldeck $\cdot$ Stefan Schönberg ${ }^{4} \cdot$ Theano Papavassiliu $^{1,2,3} \cdot$ Daniel Overhoff ${ }^{4}$ \\ ' First Department of Medicine, University Medical Center Mannheim, Faculty of Medicine Mannheim, \\ University of Heidelberg, Mannheim, Germany \\ ${ }^{2}$ European Center for AngioScience (ECAS), Mannheim, Germany \\ ${ }^{3}$ DZHK (German Center for Cardiovascular Research) Partner Site Heidelberg/Mannheim, Mannheim, \\ Germany \\ ${ }^{4}$ Institute of Clinical Radiology and Nuclear Medicine, University Medical Center Mannheim, Medical \\ Faculty Mannheim, Heidelberg University, Heidelberg, Germany \\ ${ }^{5}$ Department of Radiology and Neuroradiology, Bundeswehr Central Hospital Koblenz, Koblenz, Germany
}

\title{
Abstract
}

Background: We investigated the feasibility of evaluating coronary arteries with a contrast-enhanced (CE) self-navigated sparse isotropic 3D whole heart T1-weighted magnetic resonance imaging (MRI) study sequence.

Methods: A total of 22 consecutive patients underwent coronary angiography and/or cardiac computed tomography (CT) including cardiac MRI. The image quality was evaluated on a 3-point Likert scale. Inter-reader variability for image quality was analyzed with Cohen's kappa for the main coronary segments (left circumflex [LCX], left anterior descending $[L A D]$, right coronary artery [RCA]) and the left main trunk (LMT). Results: Inter-reader agreement for image quality of the coronary tree ranged from substantial to perfect, with a Cohen's kappa of $0.722\left(\mathrm{RCA}_{\text {mid }}\right)$ to 1 ( $(\mathrm{LCX}$ prox). The LMT had the best image quality. Image quality of the proximal vessel segments differed significantly from the mid- and distal segments ( $\mathrm{RCA}_{\text {prox }}$ Vs. $\left.\mathrm{RCA}_{\text {dist, }} p<0.05\right)$. The $\mathrm{LCX}$ segments showed no significant difference in image quality along the vessel length $(\mathrm{LCX}$ prox Vs. $\mathrm{LCX}$ dist, $p=\mathrm{n}$.s.). The mean acquisition time for the study sequence was $553 \mathrm{~s}$ $( \pm 46 s)$.

Conclusion: Coronary imaging with a sparse 3D whole-heart sequence is feasible in a reasonable amount of time producing good-quality imaging. Image quality was poorer in distal coronary segments and along the entire course of the LCX.

\section{Keywords}

Coronary artery disease $\cdot$ Whole-heart imaging $\cdot$ Noninvasive MR coronary angiography

The diagnostic algorithm for suspected coronary artery disease (CAD) is centered around the stratification of risk and assessment of pre-test probability with the help of multiple determinants such as age, family history, symptoms, and basic clinical testing. This is then followed by use of noninvasive diagnostic tools, which could potentially establish CAD in an at-risk patient. Invasive coronary angiography (ICA), once considered as an essential component of this diagnostic pathway, is now deemed to be a reasonable option if is- chemia is evident or the risk of cardiac events is high [1].

The European Society of Cardiology (ESC) has recently suggested the use of noninvasive anatomical imaging using coronary $\mathrm{CT}$ angiography (cCTA) to improve the diagnostic yield in patients with low-to-intermediate risk. However, the extensive use of CCTA is limited by routine availability, the application of an iodinated contrast agent, as well as radiation exposure [2]. 


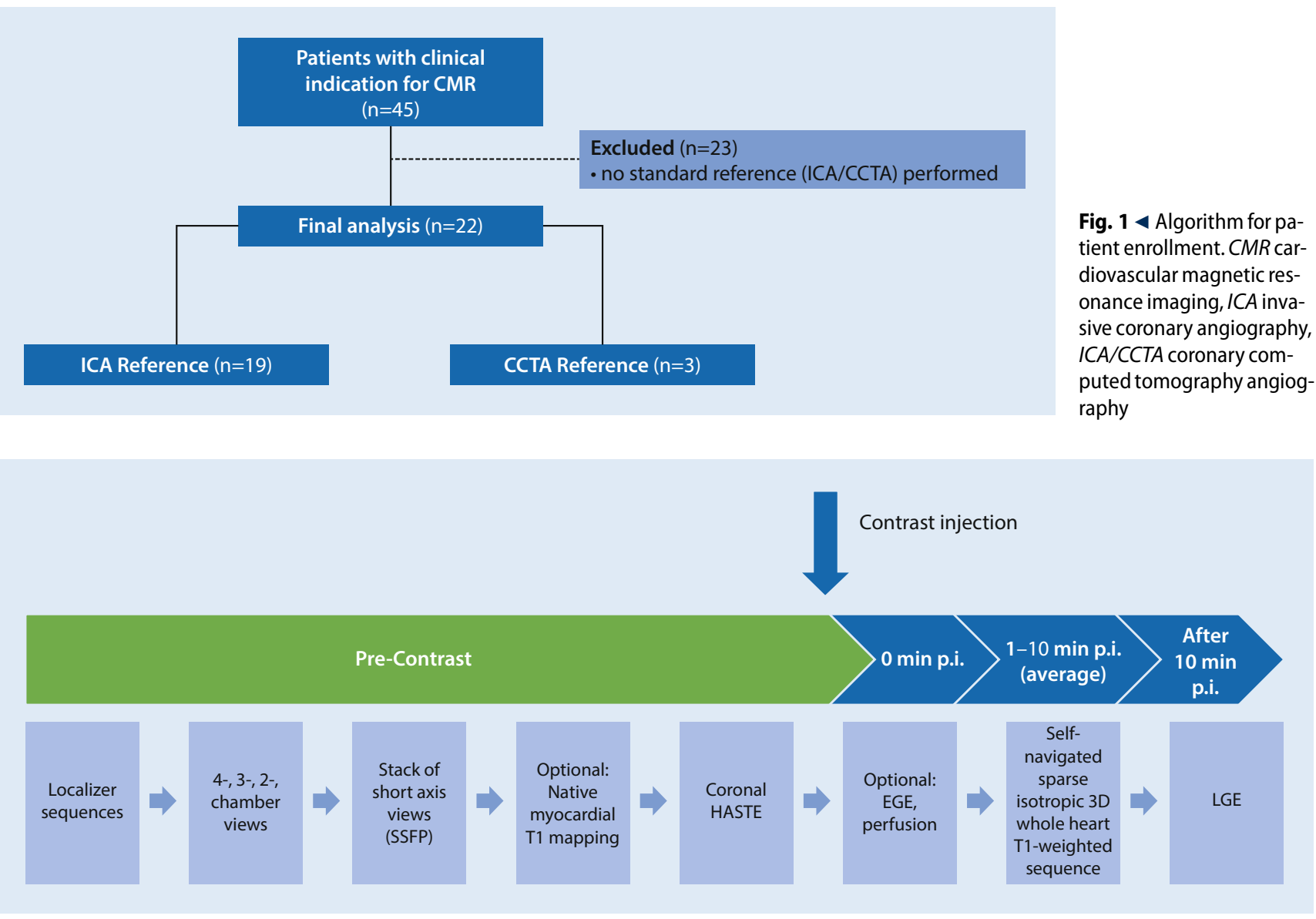

Fig. 2 \ Sequence protocol overview for whole-heart CMR. CMR cardiovascular magnetic resonance imaging, HASTE halfFourier single-shot turbo spin-echo sequence, EGE early gadolinium enhancement, SSFP steady-state free precession, LGE late gadolinium enhancement, p.i. post-injection

Magnetic resonance coronary angiography (CMRA) is a viable noninvasive alternative to $C C T A / I C A$, which could aid in the diagnosis of CAD with good accuracy in the large and proximal branches of the coronary arteries [3]. As CMRA does not suffer from beam-hardening or "blooming" artifacts caused by high-density calcification, the method could potentially outline the lumen of heavily calcified arteries of the coronary tree [4]. The introduction of three-dimensional (3D) steady-state free-precision (SSFP) whole-heart CMRA for coronary imaging enables complete visualization of the coronary arterial tree within a single axial 3D acquisition [5]. Although, the spatial and temporal resolution of these images is still inferior to CCTA, this has been mostly attributed to the lower signal-to-noise ratio (SNR), especially seen in the 1.5-T MRI systems. A significant limitation of CMRA is the comparatively lengthy acquisition times. The recent use of 3.0-T MRI systems and 32element coils potentially overcomes this limitation by improving the SNR and using parallel imaging techniques [6]. Moreover, free breathing practices and novel methods using 3D affine transformations on acquired data, processed retrospectively so as to reduce respiratory motion artifacts, have shown great promise [7].

The aim of this study was to investigate a self-navigated sparse isotropic 3D wholeheart T1-weighted sequence with an acceleration factor of around 10 , in a clinical setting, and to evaluate image quality of the coronary arteries in comparison with the reference standard ICA or CCTA.

\section{Materials and methods}

\section{Study participants and design}

This single-center study was initiated with a group of 45 prospectively enrolled pa- tients undergoing a clinically indicated contrast-enhanced (CE) cardiac MRI with the prescribed MR study sequence between March 2017 and November 2018. A total of 22 patients who further underwent an ICA and/or CCTA were included in the final analysis (0 Fig. 1).

The study included patients suspected of having CAD based on their medical history as well as those exhibiting signs and symptoms suggestive of obstructive coronary stenoses. Patients with general contraindications to CMRA (e.g., claustrophobia, metallic implants, allergy), as well as those with an acute myocardial infarction or history of coronary-artery bypass graft (CABG) surgery, were excluded from the study.

This study was approved by our local ethics committee (Medizinische Ethikkommmision II, Medizinische Fakultät Mannheim) and was conducted according to standards of the Health Insurance 



Portability and Accountability Act (HIPAA) and the Declaration of Helsinki.

\section{Data acquisition}

The CMRA was performed on a 3-T scanner system (Magnetom Skyra, Siemens Healthineers, Erlangen, Germany). Cardiac synchronization was achieved with vector electrocardiogram (ECG). Standard scout images were obtained in the axial, sagittal, and coronal views along with sequences performed in end-expiratory breath-hold covering the heart from base to apex according to retrospective ECGtriggered CMR protocols.

Cine images were acquired using a retrospective ECG-gated, balanced segmented SSFP (trueFISP) sequence in three long-axis views (two-, three-, and fourchamber view) and in multiple short-axis views, covering the entire left ventricle from base to apex. The study sequence
Fig. $3<$ Coronary imaging using invasive coronary angiography and the whole-heart sequence in coronary magnetic resonance angiography (CMRA) for visualization of the coronary arterial tree. Self-navigated 3D CMRA. Wholeheart sequence (CMRA, a) with corresponding image from the invasive coronary angiography (coronary computed tomographic angiography, b) acquired from a patient revealing the proximal left anterior descending artery (LAD; see arrow)
Both readers were blinded to the results of the reference standard ICA and CCTA, and independently evaluated the image quality of the coronary arterial tree based on a 3-point Likert scale $(1=$ insufficient visualization; 2 = sufficient visualization; $3=$ excellent visualization). The right coronary artery $(R C A)$ and the left anterior descending (LAD) artery were rated in the proximal, mid-, and distal segments. The left circumflex (LCX) was evaluated in the proximal and distal segments, and the left main trunk (LMT) as a whole.

In the second step, both readers once again independently rated the image quality of the coronary arterial tree after 3 months, while comparing it with corresponding ICA/CCTA images. Images from patients are shown in 0 Figs. 3 and 4.

\section{Conventional coronary angiography}

Invasive coronary angiography was performed on the patients using the Judkins approach either through the radial or femoral route. All relevant projections acquired during the angiogram were evaluated by an experienced cardiologist who was blinded to the results of the CMRA. A significant coronary artery stenoses was defined as luminal narrowing in diameter greater than $50 \%$.

\section{Coronary $\mathrm{CT}$ angiography}

isotropic 3D whole-heart T1-weighted prototype sequence with an acceleration factor of around 10, acquired in the waiting time between contrast administration and acquisition of the late gadolinium enhancement (LGE) sequences.

Body weight-adapted LGE images of the standard axis were acquired $10-15 \mathrm{~min}$ after i.v. injection of $0.2 \mathrm{mmol} \cdot \mathrm{kg}^{-1}$ gadoteric acid (Dotarem, Guerbet, Roissy CdG Cedex, France, Germany). The myocardial signal was "nulled" by adjusting inversion recovery (IR) time individually for every patient, typically resulting in an IR time between 240 and $300 \mathrm{~ms}$ (- Fig. 2).

\section{Whole-heart CMRA analysis}

The CMRA analysis was conducted by two radiologists with more than 5 years of experience in reading cardiovascular magnetic resonance (CMR) and CCTA images.
A third-generation dual-sourceCT (Siemens SOMATOM FORCE, Siemens Healthineers, Forchheim, Germany) was used for imaging. A specified regimen of medication consisting of sublingual nitroglycerin $(0.8 \mathrm{mg})$ and intravenous beta-blockers were given prior to the scan if deemed necessary by a radiologist. An initial dose of $80 \mathrm{~mL}$ iodinated contrast material (Iomeron 400; Bracco Imaging S.p.A., MiIan, Italy) was administered using a power injector. Coronary calcification was quantified using the Agatston score, which was calculated using a software application based on the Agatston scoring convention (syngo.via, syngo.CT CaScoring, Siemens Healthineers). The CCTA datasets were used for morphological plaque analysis and calculated by on-site prototype software (syngo.via Frontier, Coronary Plaque Analysis 2.0, Siemens Healthineers). 

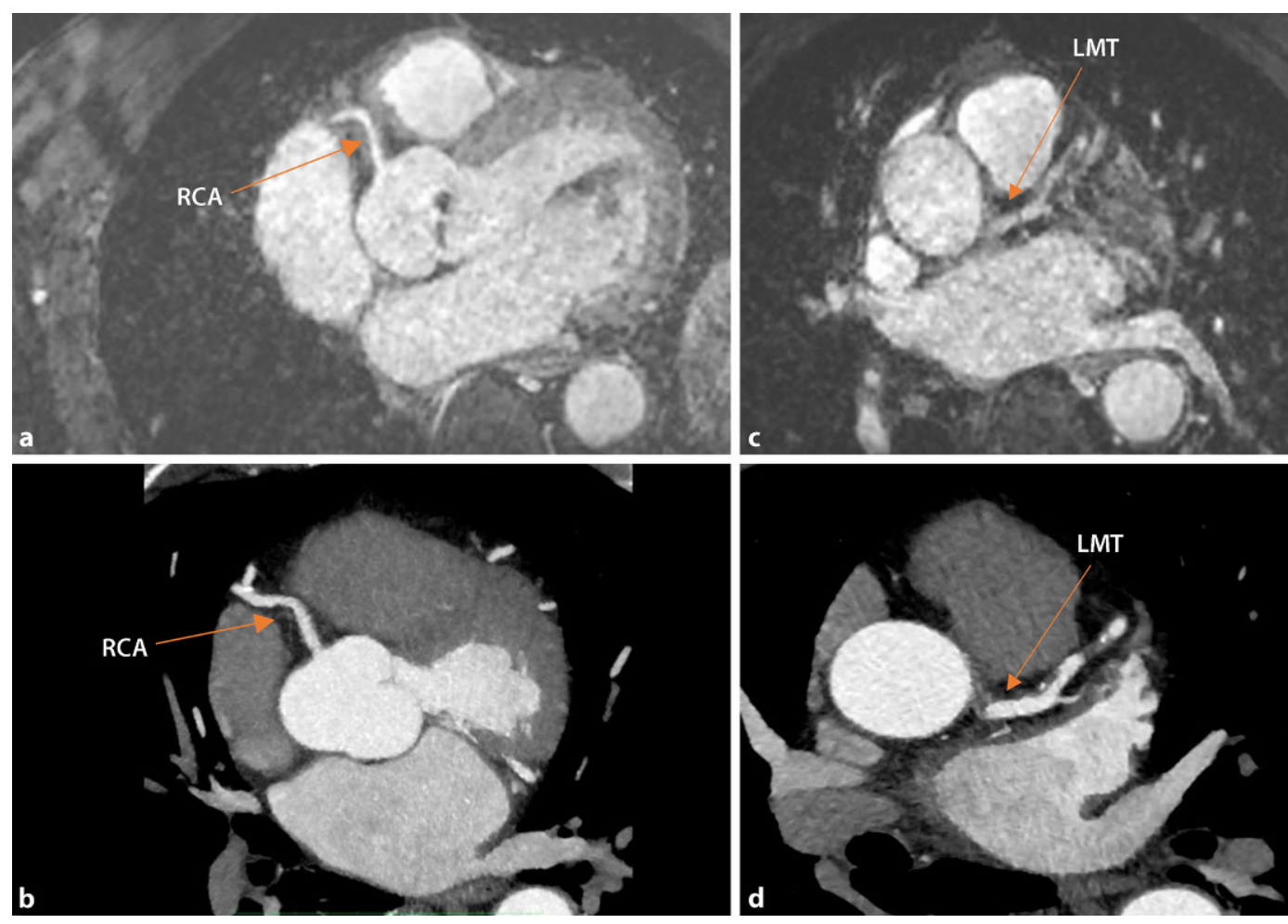

Fig. $4<$ Coronary imaging using coronary $\mathrm{CT}$ angiography and coronary magnetic resonance angiography (CMRA). Whole-heart sequence for visualization of the coronary arterial tree. a, b Selfnavigated 3D CMRA. Whole-heart sequence (CMRA, a) with corresponding coronary computed tomographic angiography (cCTA, b) acquired from a patient revealing the proximal right coronary artery (RCA). c, d Self-navigated 3D CMRA. Whole-heart sequence (CMRA, c) with corresponding $\mathrm{CCTA}$ (d) acquired from a patient revealing the left main trunk (LMT)

\section{Statistical analysis}

Statistical analysis was performed using the Statistical Package for the Social Sciences (IBM SPSS Statistics, version 20.0 for Macintosh; SPSS, Inc., Chicago, IL, USA).

All continuous data are expressed as mean \pm SD. The inclusion of variables for analysis was based on association $(p<0.05)$ in the Student $t$-test or clinical relevance. The differences between the image quality between various coronary segments were initially analyzed using the Mann-Whitney U-test. In the second step, the image quality was rated while comparing them with standard imaging from CCTA or ICA. Kappa coefficients were calculated to assess the degree of agreement for binary factors. Interreader variability for image quality was analyzed with Cohen's kappa individually for every coronary segment of the three main branches ( $L C X, L A D$, and RCA) as well as the LMT. The Wilcoxon test was used to compare the different methods and applied for results of significance on an ordinal scale. Values of $p \leq 0.05$ were considered significant.

\section{Results}

A total of 22 patients underwent both whole-heart sequences during the CMR as well as an ICA or CCTA. These were included in the study for final analysis after fulfillment of the eligibility criteria (0 Fig. 1). Free-breathing whole-heart CMRA acquisitions and reconstructions were successfully completed for all participants. The patient collective included 12 males and 10 females. The distribution of CAD in the patient population was evenly spread, with eight patients having normal coronary arteries, six patients having a triplevessel disease, five patients with singlevessel disease, and three patients with coronary atherosclerosis without significant coronary stenoses. The median age of the patient population was 64 years (24-78 years; Supplementary table).

\section{Image quality of CMRA}

The mean acquisition time for the study sequence was $553 \pm 46 \mathrm{~s}$. The CE wholeheart sequences of different patients are shown in 0 Figs. 3 and 4.

The CMRA sets showed good quality imaging in all patients. Each reader during the first sitting showed a tendency to rate a better image quality for the proximal vessel segments compared to the mid-and distal segments. The LMT had superior images as a whole $(2.41 \pm 0.67 / 2.36 \pm 0.73)$ with a significant difference in quality compared to distal ends of the coronary tree (e.g., LMT vs. $L A D_{\text {dist, }} p<0.001$ or LMT vs. $\left.\mathrm{RCA}_{\text {dist, }} p<0.001\right)$. The readers rated the proximal $L A D$ segments to have better image quality than the distal segments (Reader $1 \mathrm{LAD}_{\text {prox }}$ vs. $\mathrm{LAD}_{\text {dist, }} p<0.01$; Reader $2 \mathrm{LAD}_{\text {prox }} \mathrm{VS}$. $\left.\mathrm{LAD}_{\text {dist }} p<0.02\right)$. Similar results were also seen for the proximal RCA segments $(p=0.013$ for both readers). Interestingly, the LCX segments showed no significant difference in image quality along the course of the vessel length ( $L C X_{\text {prox }}$ Vs. $L C X_{\text {dist, }} p=$ n.s. for both readers). This could also be attributed to the poor imaging of the entire vessel as suggested by mean values derived from the ratings of both readers ( $L C X_{\text {prox }}$ $1.32 \pm 0.65 / 1.23 \pm 0.54 ; L C X_{\text {dist }} 1.09 \pm 0.43$ for both). The inter-reader variability in the first sitting varied between a Cohen's kappa index of 0.614 (for LM) and 1.0 $\left(\mathrm{LAD}_{\text {dist }}\right.$ and $\mathrm{LCX}$ disti $(\bullet$ Fig. 5a, b).

In the second step, images rendered by the CMRA were compared with the standard reference images acquired in the CCTA and/or the ICA. The proximal branches 


\begin{tabular}{|c|c|c|c|c|c|c|c|c|c|}
\hline & LMT & $L A D_{\text {prox }}$ & $\mathrm{LAD}_{\text {mid }}$ & $L A D_{\text {dist }}$ & LCX $_{\text {prox }}$ & $L C X_{\text {dist }}$ & $\mathrm{RCA}_{\text {prox }}$ & $\mathrm{RCA}_{\text {mid }}$ & $\mathrm{RCA}_{\text {dist }}$ \\
\hline LMT & & $0.034^{*}$ & $0.009^{* *}$ & $<0.001^{* *}$ & $<0.001^{* *}$ & $<0.001^{* *}$ & 0.106 & $<0.001^{* *}$ & $<0.001^{* *}$ \\
\hline$L A D_{\text {prox }}$ & $0.019^{*}$ & & 0.722 & $0.020^{*}$ & $0.003^{* *}$ & $<0.001^{* *}$ & 0.727 & $0.086^{*}$ & $0.020^{*}$ \\
\hline$L A D_{\text {mid }}$ & $0.009^{* *}$ & 0.860 & & $0.029^{*}$ & $0.003^{* *}$ & $<0.001^{* *}$ & 0.482 & 0.123 & $0.029^{*}$ \\
\hline LAD dist & $<0.001^{* *}$ & $0.010^{*}$ & 0.012 & & 0.460 & 0.050 & $0.013^{*}$ & 0.640 & 1.000 \\
\hline LCX $_{\text {prox }}$ & $<0.001^{* *}$ & $0.010^{*}$ & 0.012 & 1.000 & & 0.179 & $0.002^{* *}$ & 0.245 & 0.460 \\
\hline LCX dist & $<0.001^{* *}$ & $<0.001^{* *}$ & $<0.001$ & 0.094 & 0.094 & & $<0.001^{* *}$ & $0.024^{*}$ & 0.050 \\
\hline$R C A_{\text {prox }}$ & 0.113 & 0.601 & 0.485 & 0.006 & 0.006 & $<0.001$ & & 0.058 & $0.013^{*}$ \\
\hline$R C A_{\text {mid }}$ & $0.001^{* *}$ & 0.138 & 0.166 & 0.306 & 0.306 & 0.012 & 0.058 & & 0.640 \\
\hline $\mathrm{RCA}$ dist & $<0.001^{* *}$ & $0.020^{*}$ & 0.024 & 0.757 & 0.757 & 0.050 & $0.013^{*}$ & 0.640 & \\
\hline
\end{tabular}

a

*Mann-Whitney U Test, $p$-value $<0.05$

\begin{tabular}{|l|l|}
\hline & Reader 1 \\
\hline & Reader 2 \\
\hline
\end{tabular}

\begin{tabular}{|c|c|c|c|}
\hline & Cohens-Kappa & $\begin{array}{l}\text { Median \& Mean - } \\
\text { Reader } 1( \pm \text { SD) }\end{array}$ & $\begin{array}{r}\text { Median \& Mean- } \\
\text { Reader } 2( \pm S D)\end{array}$ \\
\hline LMT & 0.614 & $2.5(2.41 \pm 0.67)(1)$ & $2.5(2.36 \pm 0.73)(1)$ \\
\hline$L A D_{\text {prox }}$ & 0.932 & $2.0(1.86 \pm 0.77)(2)$ & $2.0(1.86 \pm 0.77)(2)$ \\
\hline$L A D_{\text {mid }}$ & 0.911 & $2.0(1.82 \pm 0.73)(1)$ & $2.0(1.77 \pm 0.69)(1)$ \\
\hline $\mathrm{LAD}_{\text {dist }}$ & 1.000 & $1.0(1.32 \pm 0.65)(1)$ & $1.0(1.36 \pm 0.66)(1)$ \\
\hline $\mathrm{LCX}_{\text {prox }}$ & 0.737 & $1.0(1.32 \pm 0.65)(0)$ & $1.0(1.23 \pm 0.54)(1)$ \\
\hline$L C X_{\text {dist }}$ & 1.000 & $1.0(1.09 \pm 0.43)(0)$ & $1.0(1.09 \pm 0.43)(0)$ \\
\hline $\mathrm{RCA}_{\text {prox }}$ & 0.860 & $2.0(2.0 \pm 0.87)(2)$ & $2.0(1.95 \pm 0.84)(2)$ \\
\hline$R C A_{\text {mid }}$ & 0.926 & $1.0(1.55 \pm 0.80)(1)$ & $1.0(1.50 \pm 0.80)(1)$ \\
\hline RCA dist & 0.888 & $1.0(1.36 \pm 0.66)(1)$ & $1.0(1.36 \pm 0.66)(1)$ \\
\hline
\end{tabular}

b

of the LAD and the RCA showed better image quality, and this was not significantly different from the LMT (LMT vs. $\operatorname{LAD}_{\text {prox }} p=$ n.s.; LMT vs. $\mathrm{RCA}_{\text {prox }} p=$ n.s. for both readers). Imaging reproduced for the LAD showed good quality throughout the vessel length $(p=$ n.s. for both readers). Nevertheless, the quality of coronary imaging did deteriorate significantly when proximal segments of the RCA were compared with the distal segments (Reader 1: $\mathrm{RCA}_{\text {prox }}$ vs. $R C A_{\text {dist, }} p=0.022$; Reader 2 :
$\mathrm{RCA}_{\text {prox }}$ Vs. RCA $\left.\mathrm{R}_{\text {dist, }} p=0.024\right)$. The LCX continued to show no significant difference in image quality along the course of the vessel length ( $L C X_{\text {prox }}$ vs. $L C X_{\text {dist }} p>0.05$ ). This could once again be attributed to the poor image quality of the vessel as a whole as suggested by the mean values $\left(L C X_{\text {prox }} 1.68 \pm 0.84 ; L \mathrm{LX}_{\text {dist }} 1.55 \pm 0.86\right.$ for both readers). The inter-reader variability in the second sitting varied between a Cohen's kappa index of 0.722 (for $R C A_{\text {mid }}$ ) and 1.0 ( $L C X_{\text {prox }}$ and $\left.L C X_{\text {dist }}\right)$. A comparison of all
Fig. 5 a Variation in quality of imaging across vessel length: first reading. b Quality of vessel imaging according to Likert scale: first reading. a Mann-Whitney $U$-test, $p<0.05$. LMT left main trunk, $L A D$ left anterior descending, $L C X$ left circumflex, $R C A$ right coronary artery segments revealed the best image quality for LMT with a mean value of $2.59 \pm 0.81$, whereas the distal LCX with a mean value of $1.55 \pm 0.86$ registered a poorer overall image quality rating (- Fig. 6a, b).

The intra-reader variability between the two sittings (• Fig. 7) showed no significant difference in interpretation of the LM imaging ( $p=$ n.s. for both readers); however, a significant improvement in the reading of the other vessels probably suggests an early learning curve. 


\begin{tabular}{|l|c|c|c|c|c|c|c|c|c|}
\hline & $L M T$ & $L A D_{\text {prox }}$ & $L A D_{\text {mid }}$ & $L A D_{\text {dist }}$ & $L C X_{\text {prox }}$ & $L C X_{\text {dist }}$ & $R C A_{\text {prox }}$ & $R_{\text {mid }}$ & $R^{\prime} A_{\text {dist }}$ \\
\hline LMT & & 0.288 & $0.038^{*}$ & $0.011^{*}$ & $<0.001^{* *}$ & $<0.001^{* *}$ & 0.718 & $0.046^{*}$ & $0.004^{* *}$ \\
\hline LAD $_{\text {prox }}$ & 0.135 & & 0.304 & 0.119 & $0.012^{* *}$ & $0.003^{* *}$ & 0.560 & 0.253 & $0.046^{*}$ \\
\hline LAD $_{\text {dist }}$ & $0.021^{*}$ & 0.312 & & 0.555 & 0.083 & $0.020^{*}$ & 0.138 & 0.746 & 0.252 \\
\hline LCX $_{\text {prox }}$ & $<0.001^{* *}$ & $0.009^{* *}$ & 0.083 & 0.232 & & 0.491 & $0.007^{* *}$ & 0.247 & 0.574 \\
\hline LCX $_{\text {dist }}$ & $<0.001^{* *}$ & $0.002^{* *}$ & $0.020^{*}$ & $0.068^{*}$ & 0.491 & & $0.002^{* *}$ & 0.089 & 0.226 \\
\hline RCA $_{\text {prox }}$ & 0.435 & 0.543 & 0.145 & $0.053^{*}$ & $0.005^{* *}$ & $0.001^{* *}$ & & 0.134 & $0.024^{*}$ \\
\hline RCA $_{\text {mid }}$ & $0.020^{*}$ & 0.218 & 0.727 & 0.862 & 0.216 & 0.071 & 0.112 & & 0.513 \\
\hline RCA $_{\text {dist }}$ & 0.002 & $0.046^{*}$ & 0.321 & 0.698 & 0.390 & 0.125 & $0.022^{*}$ & 0.601 & \\
\hline
\end{tabular}

a

\begin{tabular}{|l|l|}
\hline & Reader 1 \\
\hline & Reader 2 \\
\hline
\end{tabular}

\begin{tabular}{|l|c|c|c|}
\hline & Cohens-Kappa & $\begin{array}{c}\text { Median \& Mean } \\
\text { Reader 1 ( } \mathbf{4 S D})\end{array}$ & $\begin{array}{c}\text { Median \& Mean } \\
\text { Reader 2 ( } \pm \text { SD) }\end{array}$ \\
\hline LMT & 0.910 & $3(2.59 \pm 0.59)(1)$ & $3(2.55 \pm 0.6)(1)$ \\
\hline LAD $_{\text {prox }}$ & 0.848 & $2(2.32 \pm 0.65)(1)$ & $2(2.32 \pm 0.72)(1)$ \\
\hline LAD $_{\text {mid }}$ & 0.858 & $2(2.09 \pm 0.75)(1)$ & $2(2.09 \pm 0.75)(1)$ \\
\hline LAD $_{\text {dist }}$ & 0.862 & $2(1.95 \pm 0.76)(2)$ & $2(1.95 \pm 0.76)(2)$ \\
\hline LCX $_{\text {prox }}$ & 1.000 & $1(1.68 \pm 0.84)(1)$ & $1(1.68 \pm 0.84)(1)$ \\
\hline LCX $_{\text {dist }}$ & 1.000 & $1(1.55 \pm 0.86)(1)$ & $1(1.55 \pm 0.86)(1)$ \\
\hline RCA & & $3(2.41 \pm 0.73)(1)$ & $3(2.41 \pm 0.80)(1)$ \\
\hline RCA & & $2(2 \pm 0.87)(2)$ & $2(2 \pm 0.92)(2)$ \\
\hline RCA & 0.843 & $2(1.86 \pm 0.77)(1)$ & $2(1.87 \pm 0).(2)$ \\
\hline
\end{tabular}

b

\section{Discussion}

The use of a CMRA 3D whole-heart sequence has been studied for its clinical applications in the diagnosis of CAD as it avoids the use of radiation and potentially nephrotoxic agents used in CCTA and ICA [8]. However, the process is hampered by long acquisition times and poor image quality. The results of our study show that CMRA with a sparse 3D whole-heart T1weighted sequence with an acceleration factor of around 10, acquired in the waiting period between contrast administration and acquisition of the LGE sequences, renders good quality images with almost perfect inter-reader agreement in a reasonable amount of time. However, the image quality was shown to be poorer in the distal coronary segments as well as along the entire course of the LCX.

Early trials by Maintz et al. showed that coronary whole-heart sequences were only moderately inferior to CCTA in
Fig. $6<$ a Variation of quality of imaging across vessel length: second reading. b Quality of vessel imaging according to Likert scale: second reading Asterisk Mann-Whitney $U$-test, $p<0.05$. LMT left main trunk, LAD left anterior descending, $L C X$ left circumflex, $R C A$ right coronary artery 


\begin{tabular}{|l|c|c|}
\hline & Reader 1 & Reader 2 \\
\hline LMT & 0.102 & 0.248 \\
\hline LAD $_{\text {prox }}$ & 0.013 & 0.008 \\
\hline LAD $_{\text {mid }}$ & 0.107 & 0.053 \\
\hline LAD $_{\text {dist }}$ & 0.002 & 0.004 \\
\hline LCX $_{\text {prox }}$ & 0.046 & 0.023 \\
\hline LCX $_{\text {dist }}$ & 0.028 & 0.028 \\
\hline RCA $_{\text {prox }}$ & 0.014 & 0.008 \\
\hline RCA $_{\text {mid }}$ & 0.020 & 0.024 \\
\hline RCA $_{\text {dist }}$ & 0.018 & 0.026 \\
\hline
\end{tabular}

Fig. $7 \Delta$ Intra-reader variability ${ }^{a}$ for the patient cohort. ${ }^{a}$ Wilcoxon test. $L M T$ left main trunk, $L A D$ left anterior descending, $L C X$ left circumflex, $R C A$ right coronary artery

events and cardiac death, while providing incremental prognostic value over conventional risk factors in those without history of myocardial infarction or prior coronary artery revascularization. The presence and severity of obstructive CAD detected by CMRA was associated with worse prognosis [10].

Studies have shown that high-resolution CMRA images can be reconstructed by exploiting the inherent 3D redundancies of the coronary artery anatomy and that a high degree of sparsity could be achieved by merging information. An early study by Yang et al. showed that the 3T CE whole-heart sequence could be completed in $9.0 \pm 1.9 \mathrm{~min}$, correctly identifying CAD in 32 out of 34 patients (sensitivity of $94.1 \%$ ), while correctly ruling out CAD in 23 of 28 patients (specificity of $82.1 \%$; [11]). Another study by Kato et al. showed that the acquisition of the whole-heart CMRA sequence could be completed with an average imaging time of $9.5 \pm 3.5 \mathrm{~min}$, and the ability to diagnose coronary stenoses was quite promising with a sensitivity of $88 \%$ and specificity of $72 \%$. Data from the trial also revealed that CMRA could reliably rule out CAD with a negative predictive value (NPV) of $88 \%$ and left main disease with an NPV of $99 \%$ [12]. Similarly, Nagata et al. completed the whole-heart sequence in $6.2 \pm 2.8 \mathrm{~min}$ with a reported sensitivity and specificity of $87 \%$ and $86 \%$, respectively [13]. Our results showed that good-quality CMRA imaging with a sparse 3D whole-heart sequence, comparable to CCTA and/or ICA, was possible during the
LGE waiting period and the procedure could be completed in $553 \pm 46 \mathrm{~s}$.

The need for speed in the processing of a CMRA whole-heart sequence has meant that the quality of coronary images will be compromised. The results of our study reveal that although the proximal segments of the coronary tree could reproduce good quality images, which were comparable to images derived from CCTA and ICA, the distal end of these vessels and the LCX could not quite compare in quality. These results are similar to those reported in the study by Hamdan et al., wherein poorer image quality for the LCX was documented in the CMRA [6]. A possible explanation for this observation could be the relatively small caliber and posterior location of the LCX vessel. The increased distance between the artery and receiver coil results in a lower SNR, potentially contributing to this drawback.

The use of free-breathing techniques as used in our proposed framework has also been shown to be distinctly advantageous. For example, a free-breathing CMRA framework with a novel 3D-PROST reconstruction as proposed by Bustin et al. showed that sub-millimeter image acquisitions were possible in a fast and predictable scan time [14]. We performed the CE whole-heart sequence during the LGE waiting time in a pattern similar to a CMRA study conducted by Hirai et al., and were successful in rendering good quality images for the assessment of the coronary artery tree [15].

The potential application of this technique has interesting clinical implications.
Current guidelines define the clinical management pathway for patients suspected of having CAD using a pre-test probability model [1]. Trials such as the International Study of Comparative Health Effectiveness with Medical and Invasive Approaches (ISCHEMIA) and Clinical Outcomes Utilizing Revascularization and Aggressive Drug Evaluation (COURAGE) have pertinently questioned the singular role of coronary anatomy in guiding clinical management of obstructive CAD. It is for this reason that the combination of noninvasive anatomical as well as functional diagnostic imaging for determining the relevance of coronary stenoses before any intervention has been proposed [16].

The use of myocardial perfusion imaging (MPI) in CMR was extensively studied in the CE-MARC trial and results showed that stress CMR could offer an accurate assessment of significant single-vessel and multivessel coronary disease [17]. A recent study by Zhang et al. revealed higher sensitivity, similar specificity, and higher accuracy on a per-patient basis for the combined use of CMRA and MPI compared to MPI alone [18]. These results establish the potential for differentiating between morphological and hemodynamically significant coronary stenoses within the framework of a single procedure.

Our results help us propose the integration of a whole-heart sequence during the LGE waiting time and especially during a stress CMR. The added anatomical information is of obvious benefit as it could help direct or avoid interventions in patients with angina resistant to optimal medical therapy.

\section{Study limitations}

This single-center study is limited by the small number of patients, which influences the precision and statistical power of our analysis. This necessitates the confirmation of our results in a larger patient population. We did not measure vessel diameter or grade stenoses in the wholeheart CMRA sequence. The current wholeheart coronary MRA approach could be used for measuring luminal stenoses in the coronary arteries, as highlighted in other studies, but it would still not be able to provide sufficient information concerning 
atherosclerotic plaques in the arterial wall. Further studies are required to determine the accuracy of CMRA with radial k-space sampling for measuring vessel diameter. The lack of data describing the patient cohort and their cardiovascular burden is also a significant limitation, which would need to be studied in further analyses.

\section{Conclusion}

Coronary imaging with a sparse three-dimensional whole-heart sequence is feasible in a reasonable amount of time, producing good quality imaging. Image quality was poorer in distal coronary segments as well as along the entire course of the left circumflex artery.

\section{Corresponding address}

\section{Uzair Ansari, MD}

First Department of Medicine, University Medical Center Mannheim, Faculty of Medicine Mannheim, University of Heidelberg Theodor-Kutzer-Ufer 1-3, 68167 Mannheim, Germany uzair.ansari@umm.de

Acknowledgements. We would like to thank Christoph Forman (Application developer), Siemens Healthcare $\mathrm{GmbH}$, Erlangen, for his support.

Funding. Open Access funding enabled and organized by Projekt DEAL.

\section{Declarations}

Conflict of interest. U. Ansari, S. Janssen, S. Bau mann, M. Borggrefe, S. Waldeck, S. Schönberg, T. Papavassiliu and D. Overhoff declare that they have no competing interests.

For this article no studies with human participants or animals were performed by any of the authors. All studies performed were in accordance with the ethical standards indicated in each case.

Open Access. This article is licensed under a Creative Commons Attribution 4.0 International License, which permits use, sharing, adaptation, distribution and reproduction in any medium or format, as long as you give appropriate credit to the original author(s) and the source, provide a link to the Creative Commons licence, and indicate if changes were made. The images or other third party material in this article are included in the article's Creative Commons licence, unless indicated otherwise in a credit line to the material. If material is not included in the article's Creative Commons licence and your intended use is not permitted by statutory regulation or exceeds the permitted use, you will need to obtain permission directly from the

\section{Sparse 3D kontrastmittelverstärkte Whole Heart Bildgebung zur Darstellung der Koronararterien}

Hintergrund: Die Durchführbarkeit einer Beurteilung der Koronararterien mit einer kontrastmittelverstärkten self-navigated sparse isotropen T1-gewichteten 3D Whole Heart Magnetresonanztomographie-Bildgebungssequenz (CE-MRT) wurde ermittelt. Methoden: Bei 22 konsekutiven Patienten wurde eine Koronarangiographie und/oder eine kardiale Computertomographie (CT) einschließlich kardialer MRT durchgeführt. Die Bildqualität wurde auf einer 3-Punkt-Likert-Skala beurteilt. Mit dem KappaKoeffizienten nach Cohen für die Hauptkoronarsegmente (Ramus circumflexus der linken Koronararterie [LCX], Ramus interventricularis anterior [LAD], rechte Koronararterie $[R C A]$ ) und den linken Hauptstamm [LMT]) wurde die Inter-ReaderVariabilität für die Bildqualität ausgewertet.

Ergebnisse: Mit einem Kappa-Koeffizienten nach Cohen von 0,722 (RCA $\left.\mathrm{Aid}_{\text {mid }}\right)$ bis 1 ( $\left(\mathrm{LX}_{\text {prox }}\right.$ ) lag die Inter-Reader-Übereinstimmung für die Bildqualität des Koronarbaums zwischen beträchtlich und perfekt. Der LMT wies die beste Bildqualität auf. Die Bildqualität der proximalen Gefäßsegmente unterschied sich signifikant von den mittleren und den distalen Segmenten $\left(\mathrm{RCA}_{\text {prox }} \mathrm{vs}\right.$. $\left.\mathrm{RCA} A_{\text {dist }} ; p<0,05\right)$. Bei den LCXSegmenten ergaben sich keine wesentlichen Unterschiede in der Bildqualität über die Länge des Gefäßes ( $\mathrm{LCX}_{\text {prox }}$ vs. $\mathrm{LCX}$ dist; $p=$ n.s.). Die mittlere Aufnahmezeit für die Untersuchungssequenz betrug $553 \mathrm{~s}( \pm 46 \mathrm{~s})$.

Schlussfolgerung: Die Darstellung der Koronararterien mittels einer sparse kontrastmittelverstärkter 3D Whole Heart Sequenz ist in einem annehmbaren Zeitrahmen machbar, dabei wird eine Bildgebung von guter Qualität erzeugt. Eine schlechtere Bildqualität zeigte sich jedoch in distalen Koronarsegmenten und entlang des gesamten Verlaufs des LCX.

\section{Schlüsselwörter}

Koronare Herzkrankheit · Ganzherzbildgebung · Nicht invasive MR-Koronarangiographie

copyright holder. To view a copy of this licence, visit http://creativecommons.org/licenses/by/4.0/.

\section{References}

1. Neumann FJ, Sechtem U, Banning AP et al (2020) 2019 ESC Guidelines for the diagnosis and management of chronic coronary syndromes. Eur Heart J 41:407-477. https://doi.org/10.1093/ eurheartj/ehz425

2. Schuijf JD, Bax JJ, Shaw LJ et al (2006) Metaanalysis of comparative diagnostic performance of magnetic resonance imaging and multislice computed tomography for noninvasive coronary angiography. Am Heart J 151:404-411. https:// doi.org/10.1016/j.ahj.2005.03.022

3. Maintz D, Ozgun M, Hoffmeier A et al (2007) Wholeheart coronary magnetic resonance angiography: Value for the detection of coronary artery stenoses in comparison to multislice computed tomography angiography. Acta Radiol 48:967-973. https://doi. org/10.1080/02841850701630292

4. Liu X, Zhao X, Huang J et al (2007) Comparison of $3 \mathrm{D}$ free-breathing coronary MR angiography and 64-MDCT angiography for detection of coronary stenosis in patients with high calcium scores. AJR Am JRoentgenol 189:1326-1332. https://doi.org/ 10.2214/AJR.07.2805

5. Yoon YE, Kitagawa K, Kato S et al (2012) Prognostic value of coronary magnetic resonance angiography for prediction of cardiac events in patients with suspected coronary artery disease.
J Am Coll Cardiol 60:2316-2322. https://doi.org/ 10.1016/j.jacc.2012.07.060

6. Hamdan A, Asbach P, Wellnhofer E et al (2011) A prospective study for comparison of MR and CT imaging for detection of coronary artery stenosis. JACC Cardiovasc Imaging 4:50-61. https://doi.org/ 10.1016/j.jcmg.2010.10.007

7. Addy NO, Ingle RR, Luo J et al (2017) 3D imagebased navigators for coronary MR angiography. Magn Reson Med 77:1874-1883. https://doi.org/ 10.1002/mrm.26269

8. Nakamura M, Kido T, Kido T et al (2018) Non-contrast compressed sensing whole-heart coronary magnetic resonance angiography at 3T: A comparison with conventional imaging. Eur J Radiol 104:43-48. https://doi.org/10.1016/j.ejrad. 2018.04.025

9. Sakuma H, Ichikawa Y, Chino S et al (2006) Detection of coronary artery stenosis with wholeheart coronary magnetic resonance Angiography. J Am Coll Cardiol 48:1946-1950. https://doi.org/ 10.1016/j.jacc.2006.07.055

10. Nakamura S, Ishida M, Nakata Ket al (2021) Longterm prognostic value of whole-heart coronary magnetic resonance angiography. J Cardiovasc Magn Reson 23:1-9. https://doi.org/10.1186/ s12968-021-00749-w

11. Yang Q, Li K, Liu X et al (2009) Contrast-enhanced whole-heart coronary magnetic resonance Angiography at 3.0-T: a comparative study with X-Ray Angiography in a single center. J Am Coll Cardiol 54:69-76. https://doi.org/10.1016/j.jacc.2009.03. 016 
12. KatoS, Kitagawa K, Ishida Netal (2010) Assessment of coronary artery disease using magnetic resonance coronary angiography: a national multicenter trial. J Am Coll Cardiol 56:983-991. https://doi.org/10.1016/j.jacc.2010.01.071

13. Nagata M, Kato S, Kitagawa K et al (2011) Diagnostic accuracy of 1.5-T unenhanced wholeheart coronary MR Angiography performed with 32-channel cardiac coils: initial single-center experience. Radiology 259:384-392. https://doi. org/10.1148/radiol.11101323

14. Bustin A, Ginami G, Cruz G et al (2019) Fiveminute whole-heart coronary MRA with submillimeter isotropic resolution, $100 \%$ respiratory scan efficiency, and 3D-PROST reconstruction. Magn Reson Med 81:102-115. https://doi.org/10. 1002/mrm.27354

15. Hirai K, Kido T, Kido T et al (2020) Feasibility of contrast-enhanced coronary artery magnetic resonance angiography using compressed sensing. J Cardiovasc Magn Reson 22:1-10. https://doi.org/ 10.1186/s12968-020-0601-0

16. Maron DJ, Hochman JS, Reynolds HR et al (2020) Initial invasive or conservative strategy for stable coronary disease. N Engl J Med 382:1395-1407. https://doi.org/10.1056/nejmoa1915922

17. Greenwood JP, Maredia N, Younger JF et al (2012) Cardiovascular magnetic resonance and singlephoton emission computed tomography for diagnosis of coronary heart disease (CE-MARC): a prospective trial. Lancet 379:453-460. https:// doi.org/10.1016/S0140-6736(11)61335-4

18. Zhang L, Song X, Dong L et al (2018) Additive value of 3T cardiovascular magnetic resonance coronary angiography for detecting coronary artery disease. J Cardiovasc Magn Reson 20:1-8. https://doi.org/ $10.1186 / \mathrm{s} 12968-018-0450-2$

\section{Das Wichtigste in Kürze: Abbildungen}

\section{Abbildungsmanagement}

Bitte beachten Sie, dass alle Abbildungen in Ihrem Manuskript mit einer Quellenangabe versehen sein müssen, sofern sie nicht eigens für die Publikation des geplanten Beitrags von der Autorenschaft erstellt wurden.

\section{Übernahmen}

Bereits publizierte Abbildungen (auch in modifizierter Form) aus Publikationen anderer Verlage können nur berücksichtigt werden, wenn die zeitlich unbefristete Abdruckgenehmigung (print, online, mobil) des Inhabers der Nutzungsrechte von Ihnen vorgelegt werden kann.

> Weiterführende Informationen und Links zur Rechteeinholung finden Sie über den QRCode.

\section{Copyright Clearance Center}

Die meisten großen Verlage arbeiten über das Copyright Clearance Center (CCC)/RightsLink. Zu dem Genehmigungsformular gelangen Sie über einen Link an den Online-Artikeln/Kapiteln mit der gewünschten Abbildung.

> Weiterführende Informationen mit Kurzanleitung finden Sie über den QR-Code.

\section{Tipp: Tabellen}

Für einfache Tabellen, die Sie aus anderen Publikationen übernehmen, benötigen Sie keine Abdruckgenehmigung. Jedoch ist auch hier die Quelle zu nennen.

Vorsicht: Fotos erkennbarer Personen Gesichter werden vom Verlag grundsätzlich unkenntlich gemacht. Soll die abgebildete Person erkennbar bleiben, benötigen Sie die zeitlich und räumlich unbeschränkte Einwilligung zur Nutzung des Fotos.

Mehr Informationen auf www.springermedizin.de/schreiben

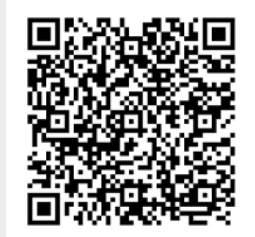

